BRAVILLIAN JOURNAL

www.bjournal.com.br
ISSN 0100-879X

Volume 43 (4) 268-380 April 2011

BIOMEDICAL SCIENCES

AND

CLINICAL INVESTIGATION

Braz J Med Biol Res, April 2011, Volume 44(4) 337-344

Vascular adaptive responses to physical exercise and to stress are affected differently by nandrolone administration

T. Bruder-Nascimento and S. Cordellini

The Brazilian Journal of Medical and Biological Research is partially financed by

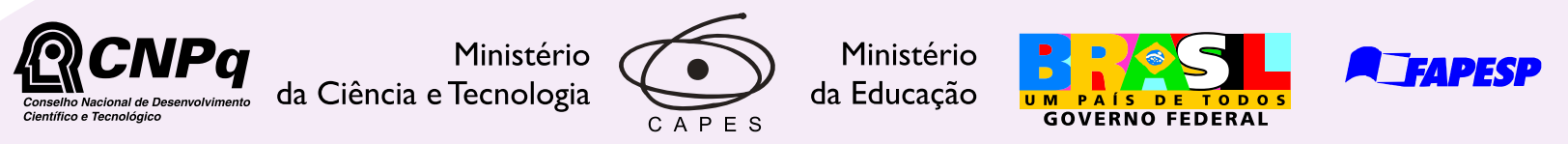

Institutional Sponsors
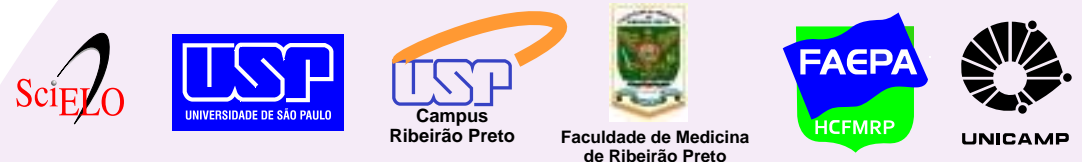

Ф) SHIMADZU HO

GE Healthcare

ana
Hotsite of proteomics metabolomics developped by:

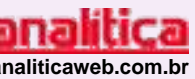

Thermo SCIENTIFIC 


\title{
Vascular adaptive responses to physical exercise and to stress are affected differently by nandrolone administration
}

\author{
T. Bruder-Nascimento and S. Cordellini \\ Departamento de Farmacologia, Instituto de Biociências, \\ Universidade Estadual Paulista "Júlio de Mesquita Filho", Botucatu, SP, Brasil
}

\begin{abstract}
Androgenic anabolic steroid, physical exercise and stress induce cardiovascular adaptations including increased endothelial function. The present study investigated the effects of these conditions alone and in combination on the vascular responses of male Wistar rats. Exercise was started at 8 weeks of life (60-min swimming sessions 5 days per week for 8 weeks, while carrying a $5 \%$ body-weight load). One group received nandrolone $(5 \mathrm{mg} / \mathrm{kg}$, twice per week for 8 weeks, im). Acute immobilization stress $(2 \mathrm{~h})$ was induced immediately before the experimental protocol. Curves for noradrenaline were obtained for thoracic aorta, with and without endothelium from sedentary and trained rats, submitted or not to stress, treated or not with nandrolone. None of the procedures altered the vascular reactivity to noradrenaline in denuded aorta. In intact aorta, stress and exercise produced vascular adaptive responses characterized by endothelium-dependent hyporeactivity to noradrenaline. These conditions in combination did not potentiate the vascular adaptive response. Exercise-induced vascular adaptive response was abolished by nandrolone. In contrast, the aortal reactivity to noradrenaline of sedentary rats and the vascular adaptive response to stress of sedentary and trained rats were not affected by nandrolone. Maximum response for $7-10$ rats/group $(\mathrm{g})$ : sedentary $3.8 \pm 0.2 \mathrm{vs}$ trained $3.0 \pm 0.2^{*}$; sedentary/stress $2.7 \pm 0.2 \mathrm{vs}$ trained/stress $3.1 \pm 0.1^{*}$; sedentary/nandrolone $3.6 \pm 0.1 \mathrm{vs}$ trained/nandrolone $3.8 \pm 0.1$; sedentary/stress/nandrolone $3.2 \pm 0.1 \mathrm{vs}$ trained/stress/nandrolone $2.5 \pm 0.1^{*} ;{ }^{*} \mathrm{P}<0.05$ compared to its respective control. Stress and physical exercise determine similar vascular adaptive response involving distinct mechanisms as indicated by the observation that only the physical exercise-induced adaptive response was abolished by nandrolone.
\end{abstract}

Key words: Stress; Physical exercise; Nandrolone; Vascular reactivity

\section{Introduction}

Regular physical exercise has been associated with a reduced incidence of cardiovascular diseases. Endurance training of healthy sedentary human subjects results in increased cardiac output and stroke volume (1). Chronic exercise is also known to improve the vasodilatory mechanisms mediated by endothelium-dependent relaxing factors in the cardiac and skeletal muscles, as well as kidney, cutaneous and other vascular beds (2-4). Decreased blood pressure induced by exercise training was also reported in hypertensive subjects and spontaneously hypertensive rats $(5,6)$.

To potentiate the physiological effects of physical training, many athletes use ergogenic substances. The use of anabolic androgenic steroids (AAS) is no longer limited to athletes and body builders. Adolescents and adults with no primary interest in sports, but who are interested in weight gain and improvement of their physical appearance have started to abuse AAS. The intake of these steroids has been associated with vascular complications, cardiomyopathy, coronary atherosclerosis, and cardiac hypertrophy. Furthermore, in several clinical reports, AAS intake was associated with an acute myocardial infarct $(7,8)$. It has been reported that treatment with the AAS nandrolone worsens an animal's endothelial and vascular smooth muscle function (9-14). In fact, the endothelial cell plays an important role in the cardiovascular system by producing a variety of potent vasoactive agents. Changes in endothelial cell function are implicated in a variety of pathophysiological processes, such as steroid abuse, and the restoration of endothelial function appears to be a promising therapeutic

Correspondence: S. Cordellini, Departamento de Farmacologia, Instituto de Biociências, UNESP, Rubião Júnior, s/n, 18618-970 Botucatu, SP, Brasil. Fax: +55-14-3815-3744. E-mail: cordelli@ibb.unesp.br

Received September 29, 2010. Accepted February 18, 2011. Available online April 1, 2011. Published April 11, 2011. 
approach (15-17).

Stress is another physiological condition that involves circulatory changes. Although virtually all organs are affected by exposure to stressors, the neuroendocrine, cardiovascular, immune, and gastrointestinal systems are the first to experience functional changes (18). Similarly to that observed in exercise training, the stress-induced vascular changes are dependent on both endothelial integrity and hyperactivity of the endothelial nitric oxidesystem $(15,17,19)$.

Despite the reports of vascular reactivity changes related to stress, exercise and abuse of steroids isolated, the circulatory adaptation to these perturbations in combination requires further investigation. Thus, given the frequent use of AAS by sport athletes and the general population as well as the potential health risks of stressful stimuli, the objective of the present study was to evaluate the effect of exercise training, stress and AAS administration alone or in combination on vascular function, focusing on the endothelial and smooth muscle cells.

\section{Material and Methods}

\section{Animals}

Experiments were performed on male Wistar rats with 6 weeks of age and $250-270 \mathrm{~g}$ body weight at the beginning of the experiments. Lights in the animal room were set on a $12: 12-\mathrm{h}$ cycle with temperature maintained at $22 \pm 1^{\circ} \mathrm{C}$. The animals were housed 3 per cage and were given regular laboratory chow and water ad libitum.

The experimental procedures were in accordance with the principles and guidelines of the National Council for Control of Animal Experimentation and were approved by the Ethics Committee of the Instituto de Biociências, UNESP, Botucatu (protocol \#67/03-CEEA).

\section{Body and organ weights}

The weights of the body, adrenals, left ventricle, prostate, testes, and seminal vesicles were measured in sedentary and trained rats treated or not with nandrolone. The animals were weighed weekly throughout the experimental period. Since the weight of the adrenals correlates with stress level, it was employed to assess the efficacy of stress induction. Moreover, since the weights of the prostate, testes and seminal vesicle correlate with sex hormone levels, they were employed to assess the efficacy of treatment with the exogenous anabolic androgenic steroid nandrolone. Finally, cardiac hypertrophy was assessed by left ventricle weight normalized for body weight (LV weight/BW).

\section{Measurement of blood pressure}

Systolic blood pressure was determined in conscious rats using tail-cuff plethysmography (Narco Bio-Systems, USA) immediately before starting treatment and weekly until the death of the animal. The rats were prewarmed for
10 to $15 \mathrm{~min}$ and placed into a restrainer for blood pressure measurement. Three consecutive recordings ( 1 min apart) were performed, and the mean of these three measurements was recorded.

\section{Adaptation period}

To avoid a considerable loss of rats and to reduce the animals' stress, the rats from the training groups were submitted to a gradual but brief adaptation period. During the first pre-training week these animals ( 6 weeks old) were placed exposed to increasing volumes of heated water and periods of exposure $\left(28 \pm 1{ }^{\circ} \mathrm{C} ; 15-60 \mathrm{~min} /\right.$ day, 5 weekly sessions) within a tank $(35 \times 17 \times 50 \mathrm{~cm})$ in order to adapt to the water. Subsequently, the rats were submitted to a second pre-training week consisting of forced swimming sessions in water at $28 \pm 1{ }^{\circ} \mathrm{C}$ for 60 min, carrying a load strapped to their chests. The workload was gradually increased (1-5\% of body weight) until the rats could swim for 60 min wearing a chest load weighing $5 \%$ of body weight. Thereafter, the workload was constant.

\section{Exercise training program}

Exercise training consisted of a forced swimming session once a day for a period of 8 weeks ( 5 days/week). Rats were submitted individually to a forced swimming session in warmed water at $28 \pm 1^{\circ} \mathrm{C}$ for 60 min, carrying a load weighing $5 \%$ of body weight strapped to their chests. The sessions were performed between 1:00 and 2:00 pm. During the exercise session, the sedentary rats were kept in their home cages. This swimming protocol has been characterized previously as being of low to moderate intensity and of long duration (20). Forty-eight hours after the last exercise session, the animals were sacrificed by decapitation.

\section{Treatment with nandrolone decanoate}

Eight-week-old rats were randomized into 4 groups (7-10 rats/group): sedentary vehicle-treated (vehicle = corn oil: $0.2 \mathrm{~mL}$ body weight, twice per week, intramuscularly, for 8 weeks), trained vehicle-treated, sedentary nandrolone-treated (nandrolone decanoate, Deca Durabolin ${ }^{\circledR}$, Organon do Brasil, Brazil, $5 \mathrm{mg} / \mathrm{kg}$ body weight twice a week, intramuscularly, for 8 weeks) (12), and trained nandrolone-treated. This dose is comparable to the dose that has been reported to be frequently used by heavy AAS abusers (21).

\section{Stress induction}

Forty-eight hours after the last exercise session, a group of trained rats, treated or not with nandrolone, was submitted to a single stress session (Train/St and Train/ $\mathrm{Nand} / \mathrm{St}$, respectively). Additionally, a group of 16-weekold sedentary rats treated or not with nandrolone was also submitted to a single stress session (Sed/St and Sed/ $\mathrm{Nand} / \mathrm{St}$, respectively). The stressor agent consisted of immobilization for $2 \mathrm{~h}$ in a $5 \times 27-\mathrm{cm}$ metal tube, individu- 
ally adapted to provide a tight restriction of movements, but allowing the animal to breathe normally. This acute stress exposure took place between 10:00 am and 2:00 $\mathrm{pm}$. During the stress session, the non-stressed rats were kept in their home cage. Immediately after stress exposure the rats were sacrificed by decapitation.

\section{Vascular reactivity protocol}

Immediately after animal sacrifice, the descending thoracic aorta was excised and trimmed free of adhering fat and connective tissue. Two transverse rings of the same artery, each about $4 \mathrm{~mm}$ in length, were cut and mounted at the optimal length for isometric tension recording in organ chambers (17). One ring served as control, while the endothelium was mechanically removed from the other by gently rubbing the luminal surface. Briefly, preparations were mounted in organ baths containing $7 \mathrm{~mL}$ KrebsHenseleit solution of the following composition: $113.0 \mathrm{mM}$ $\mathrm{NaCl}, 4.7 \mathrm{mM} \mathrm{KCl}, 2.5 \mathrm{mM} \mathrm{CaCl}_{2}, 1.2 \mathrm{mM} \mathrm{KH}_{2} \mathrm{PO}_{4}, 1.1$ $\mathrm{mM} \mathrm{MgSO}_{4}, 25.0 \mathrm{mM} \mathrm{NaHCO}_{3}, 11.0 \mathrm{mM}$ glucose, and 0.11 $\mathrm{mM}$ ascorbic acid. The bathing fluid, kept at $36.0 \pm 0.5^{\circ} \mathrm{C}$, was saturated with a gas mixture of $95 \% \mathrm{O}_{2}$ and $5 \% \mathrm{CO}_{2}$. The preparations were allowed to equilibrate for at least $1 \mathrm{~h}$ under a resting tension of $1.5 \mathrm{~g}$, which is optimal for inducing maximum contraction. Tension was recorded with a physiograph (Ugo Basile, Italy).

Cumulative concentration-effect curves were constructed from the response of the tissue to noradrenaline. At the end of the curves, single doses of $1.0 \mu \mathrm{M}$ acetylcholine or 0.1 $\mathrm{mM}$ sodium nitroprusside were used to test the integrity of endothelial and smooth muscle layers, respectively. Endothelium and smooth muscle were considered to be intact if the acetylcholine and sodium nitroprusside-induced relaxation of the precontracted aorta was greater than 60 and $99 \%$, respectively.

\section{Data analysis and statistics}

The concentration of vasoactive agents producing a response that was $50 \%$ of the maximum $\left(E_{50}\right)$ was calculated in each experiment. Maximal responses (grams of tension) and blood pressure $(\mathrm{mmHg})$, reported as means \pm $\mathrm{SEM}$, and $\mathrm{EC}_{50}$ values, reported as median with $95 \%$ confidence intervals, were compared by multifactorial ANOVA (SIGMASTAT 2.0). Nandrolone treatment, exercise training and stress were the factors in the analysis. A $P$ value less than 0.05 was considered to be statistically significant. The Tukey multiple comparisons test was used to test differences between means.

\section{Drugs and solutions}

The following drugs were used: acetylcholine bromide, noradrenaline bitartrate, sodium nitroprusside (all obtained from Sigma, USA) and nandrolone decanoate. All drugs, except nandrolone, were dissolved in Krebs-Henseleit solution. Nandrolone was dissolved in corn oil.

\section{Results}

\section{Effects of exercise training associated or not with nandrolone treatment on body and organ weights and blood pressure}

The evolution of body weight was similar for all experimental groups [final body weight $(\mathrm{g})$ : Sed $=458.3 \pm 24.5$, Train $=426.6 \pm 30.1$, Sed/Nand $=439.4 \pm 27.7$ and Train/ Nand $=446.3 \pm 25.5, P>0.05, N=7-10]$. The evolution of blood pressure did not differ between sedentary and trained rats, but was significantly increased by nandrolone treatment in both groups ( $\triangle \mathrm{PA} \mathrm{mmHg}$ : Sed $9.7 \pm 3.1$; Train 7.6 \pm 4.6; Sed/Nand $25.4 \pm 8.5^{*}$; Train/Nand $24.6 \pm 6.0^{*} ;{ }^{*} \mathrm{P}<$ 0.05 related to the respective group without nandrolone; Figure 1).

Among the different procedures, only exercise training induced cardiac hypertrophy (Table 1). The administration of nandrolone induced a further increase in prostate weight and seminal vesicles and a decrease in testicular weight, both in sedentary and trained rats (Table 1). Finally, stress exposure induced a decrease in adrenal weight in all groups (Table 1).

\section{Vascular responsiveness to noradrenaline}

The exposure to stress and to exercise training reduced the maximal responses to noradrenaline (NA) of the intact aorta compared to non-stressed sedentary rats. Moreover, the combination of these procedures did not potentiate aortal hyporeactivity to the vasoconstriction agent (Figure $2 \mathrm{~A}$ and B; Tables 2 and 3 ).

Treatment with nandrolone did not alter the reactivity to

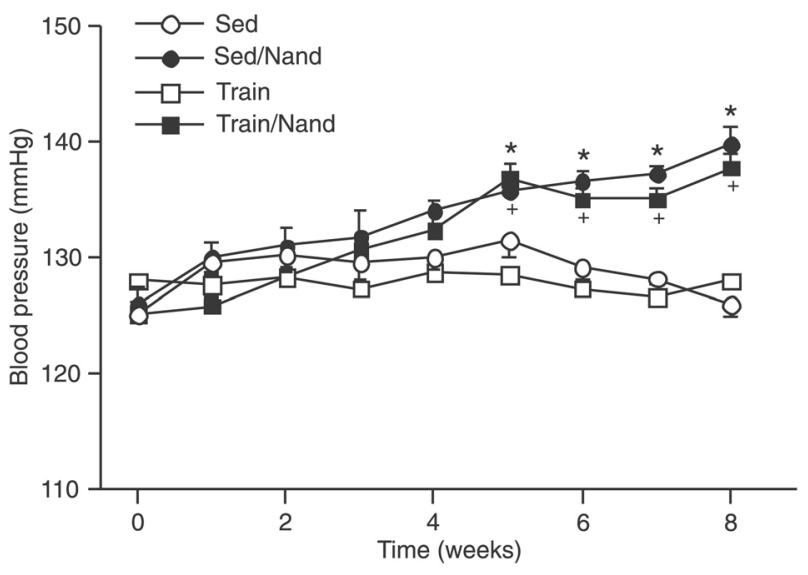

Figure 1. Effect of nandrolone on systolic blood pressure of sedentary (Sed) and trained (Train) rats. Physical training $=60$ min swimming session 5 days per week for 8 weeks, with a $5 \%$ body weight load attached to the chest of rats treated or not with nandrolone decanoate (Nand, Deca Durabolin ${ }^{\circledR}, 5 \mathrm{mg} / \mathrm{kg}$ body weight twice per week for 8 weeks, im). Data are reported as means \pm SEM for $7-10$ animals per group. ${ }^{*} P<0.05$ relative to Sed; ${ }^{+} \mathrm{P}<0.05$ relative to Train (ANOVA and Tukey test). 
Table 1. Effects of physical training, acute stress and nandrolone administration on tissue weight of rats.

\begin{tabular}{|c|c|c|c|c|c|}
\hline & \multicolumn{5}{|c|}{ Tissue weight } \\
\hline & Left ventricle/body weight & Testis (g) & Prostate (g) & Seminal vesicle $(\mathrm{g})$ & Adrenals $(g \times 100)$ \\
\hline \multicolumn{6}{|l|}{ Sedentary } \\
\hline Control & $1.92 \pm 0.75$ & $3.51 \pm 0.09$ & $0.52 \pm 0.01$ & $0.54 \pm 0.02$ & $8.04 \pm 0.53$ \\
\hline Stress & $1.90 \pm 0.42$ & $3.30 \pm 0.11$ & $0.49 \pm 0.04$ & $0.52 \pm 0.03$ & $5.84 \pm 0.42^{+}$ \\
\hline Nandrolone & $1.95 \pm 0.6$ & $2.95 \pm 0.02^{+}$ & $0.69 \pm 0.02^{+}$ & $0.78 \pm 0.02^{+}$ & $7.70 \pm 0.24$ \\
\hline Nandrolone/stress & $1.91 \pm 0.31$ & $2.81 \pm 0.10^{+}$ & $0.73 \pm 0.04^{+}$ & $0.76 \pm 0.03^{+}$ & $5.89 \pm 0.28^{+}$ \\
\hline \multicolumn{6}{|l|}{ Physical training } \\
\hline Control & $2.25 \pm 0.10^{*}$ & $3.46 \pm 0.09$ & $0.52 \pm 0.01$ & $0.51 \pm 0.04$ & $7.91 \pm 0.50$ \\
\hline Stress & $2.31 \pm 0.55^{*}$ & $3.27 \pm 0.07$ & $0.47 \pm 0.01$ & $0.58 \pm 0.02$ & $6.18 \pm 0.20^{+}$ \\
\hline Nandrolone & $2.35 \pm 0.71^{*}$ & $2.75 \pm 0.12^{+}$ & $0.71 \pm 0.04^{+}$ & $0.81 \pm 0.03^{+}$ & $7.59 \pm 0.17$ \\
\hline Nandrolone/stress & $2.46 \pm 0.10^{*}$ & $2.61 \pm 0.15^{+}$ & $0.72 \pm 0.05^{+}$ & $0.84 \pm 0.02^{+}$ & $5.70 \pm 0.40^{+}$ \\
\hline
\end{tabular}

Data are reported as means \pm SEM for 7-10 animals/group. Acute stress $=$ immobilization for $2 \mathrm{~h}$; physical training $=60$-min swimming session for 5 days per week for 8 weeks, with a $5 \%$ body weight load attached to the chest; nandrolone treatment $=$ Deca Durabolin ${ }^{\circledR}, 5 \mathrm{mg} / \mathrm{kg}$ body weight twice per week for 8 weeks, im. ${ }^{*} \mathrm{P}<0.05$ relative to the sedentary control group; ${ }^{+} \mathrm{P}<0.05$ relative to the respective control group (ANOVA and Tukey test).

Sedentary

A

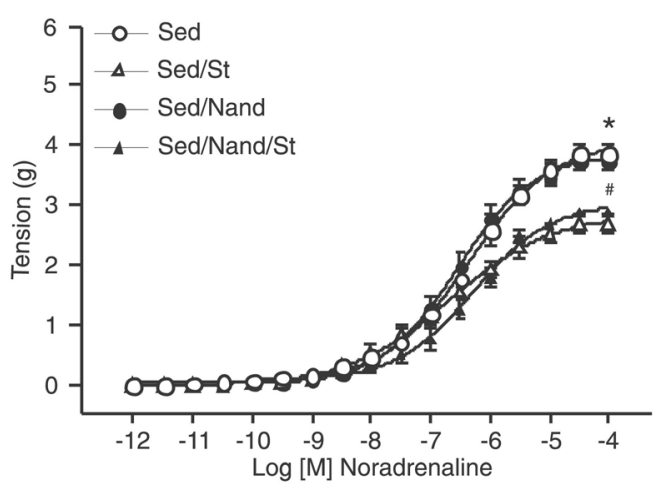

Trained

C

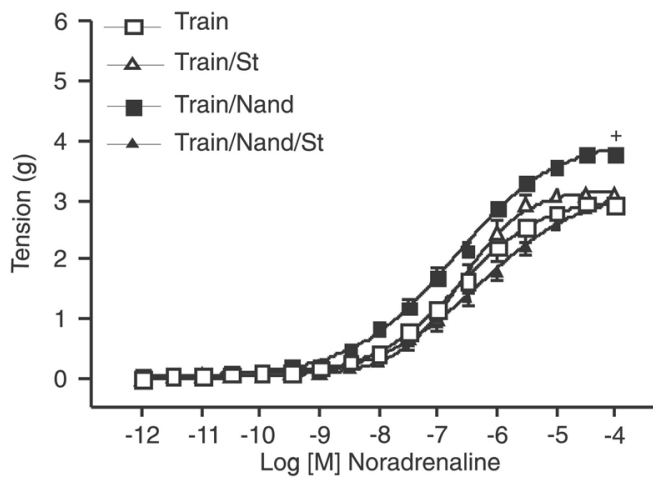

B

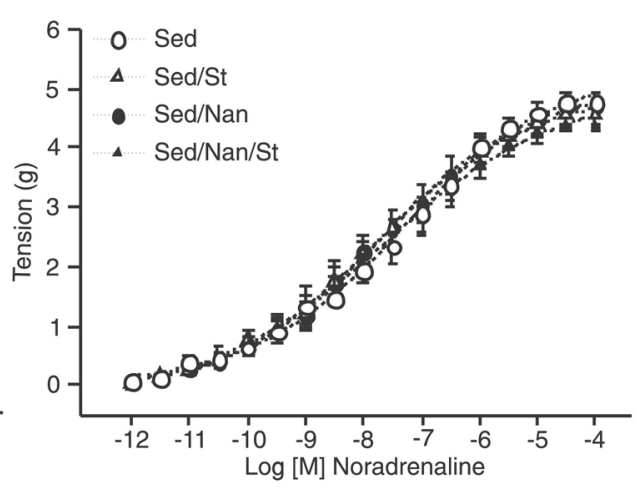

$\mathrm{D}$

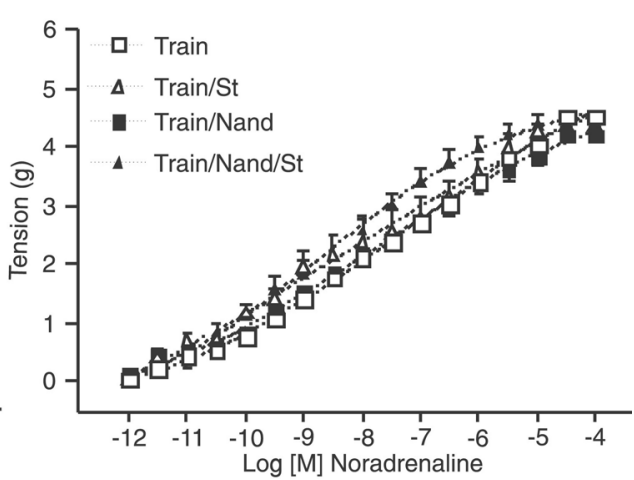

Figure 2. Concentrationeffect curves for noradrenaline obtained with two rings, one with (solid lines) and the other without (dotted lines) endothelium, of the same thoracic aorta from 16-week-old sedentary (Sed, A and B) and trained rats (Train, $C$ and D). Physical training $=60$ min swimming session 5 days per week for 8 weeks, with a $5 \%$ body weight load attached to the chest of rats submitted or not to acute stress (St, immobilization for $2 \mathrm{~h}$ ) and treated or not with nandrolone decanoate (Nand, Deca Durabolin $^{\circledR}, 5 \mathrm{mg} / \mathrm{kg}$ body weight twice per week for 8 weeks, im). Data are reported as means \pm SEM for 7-10 animals per group. * $P$ $<0.05$ relative to Sed/St; $\# \mathrm{P}<0.05$ relative to Sed/ $\mathrm{Nand} / \mathrm{St} ;{ }^{+} \mathrm{P}<0.05$ relative to Train/Nand/St (ANOVA and Tukey test). 
NA of the intact aorta from non-stressed sedentary rats, but abolished the aortal hyporeactivity induced by exercise training (Figure 2A and C, Table 2). In contrast, the hyporeactivity to NA induced by stress in both sedentary and trained rats was not altered by nandrolone treatment (Figure 2B and D, Table 2). None of the experimental procedures provoked any change in sensitivity to NA of the intact aorta.

Removal of the endothelium caused leftward shifts of the curve and elevated maximum responses to NA that were similar in aortas from the different experimental groups. Moreover, none of the experimental procedures provoked any change in the reactivity to NA of the denuded aorta (Figure 2, Tables 2 and 3).

\section{Discussion}

\section{Effectiveness of the experimental protocols}

In the present study, exercise training produced a negative effect on body weight gain, confirming findings in the literature showing that physical exercise counteracts overweight since it reduces the energetic balance by increasing energy expenditure $(12,22)$.

The literature also shows that anabolic steroids induce testicular atrophy (23) and increase the weights of the prostate and seminal vesicles $(24,25)$. Supporting these findings, in the present study nandrolone treatment induced gains in seminal vesicle and prostate weight as well as a decrease in testicular weight, confirming the effectiveness of the treatment protocol used.

Various investigators have used the fresh weight of the adrenal gland, an organ that responds to stress, as indicative of stressogenic conditions. The weight of the adrenal gland may be reduced or may remain unchanged after exposure to acute stress, but is often increased by chronic stress (26-28). In the present study, the mean fresh weight of the adrenal glands was significantly reduced, showing that acute stress was effective in the experimental protocols proposed. In contrast, physical exercise did not alter the adrenal weight, suggesting that the training protocol used did not represent a stressogenic condition.

Independently of nandrolone treatment, the training protocol produced left ventricular hypertrophy. It is known that physical exercise is a stimulus for the development of left ventricular hypertrophy, which occurs to maintain not only the relative constancy of ventricular wall stress but also the adequacy of the stroke volume, so that the resulting structural changes depend on the nature, duration and intensity of exercise (29). Hypertrophy may represent a physiological and beneficial cardiac adaptation, usually associated with enhanced heart function (21). Thus, the data show the effectiveness of the physical exercise protocol used.

\section{Impact of different risk factors in combination on the cardiovascular response}

The effects of physical exercise on the blood pressure of normotensive animals and humans have been reported to be minimal $(20,30)$. In agreement with these data, the

Table 2. Maximum responses to noradrenaline obtained with two aorta rings, one with and the other without endothelium, of the same thoracic aorta from sedentary and trained rats, submitted or not to stress and treated or not with nandrolone.

\begin{tabular}{lcc}
\hline & \multicolumn{2}{c}{ Maximal responses $(\mathrm{g})$} \\
\cline { 2 - 3 } & With endothelium & Without endothelium \\
\hline Sedentary & & \\
Control & $3.84 \pm 0.15$ & $4.75 \pm 0.18^{+}$ \\
Stress & $2.73 \pm 0.17^{*}$ & $4.31 \pm 0.13^{+}$ \\
Nandrolone & $3.62 \pm 0.13$ & $4.57 \pm 0.26^{+}$ \\
Nandrolone/stress & $3.17 \pm 0.10^{*}$ & $4.35 \pm 0.14^{+}$ \\
Physical training & & \\
Control & $3.00 \pm 0.18^{*}$ & $4.49 \pm 0.19^{+}$ \\
Stress & $3.11 \pm 0.14^{*}$ & $4.31 \pm 0.13^{+}$ \\
Nandrolone & $3.80 \pm 0.09$ & $4.25 \pm 0.01^{+}$ \\
Nandrolone/stress & $2.50 \pm 0.13^{*}$ & $4.57 \pm 0.19^{+}$ \\
\hline
\end{tabular}

Data are reported as means \pm SEM for 7-10 animals/group. Acute stress $=$ immobilization for $2 \mathrm{~h}$; physical training $=60$-min swimming session 5 days per week for 8 weeks, with a $5 \%$ body weight load attached to the chest; nandrolone treatment $=$ Deca Durabolin ${ }^{\circledR}, 5 \mathrm{mg} / \mathrm{kg}$ body weight twice per week for 8 weeks, im. ${ }^{*} P<0.05$ relative to the sedentary control group; ${ }^{+} P<0.05$ relative to aorta with endothelium (ANOVA and Tukey test).

Table 3. $\mathrm{EC}_{50}$ values for noradrenaline obtained with two rings, one with and the other without endothelium, of the same thoracic aorta from sedentary and trained rats, submitted or not to stress and treated or not with nandrolone.

\begin{tabular}{lll}
\hline & \multicolumn{2}{c}{$\mathrm{EC}_{50}\left(\times 10^{-7} \mathrm{M}\right)$} \\
\cline { 2 - 3 } & With endothelium & Without endothelium \\
\hline Sedentary & & \\
Control & $4.43(1.79-6.59)$ & $0.16^{*}(0.01-2.56)$ \\
Stress & $1.38(0.56-3.67)$ & $0.17^{*}(0.04-0.85)$ \\
Nandrolone & $3.10(2.09-4.62)$ & $0.06^{*}(0.02-0.15)$ \\
Nandrolone/stress & $3.26(1.14-9.31)$ & $0.12^{*}(0.03-0.50)$ \\
Physical training & & \\
Control & $2.33(0.72-7.56)$ & $0.04^{*}(0.01-0.12)$ \\
Stress & $2.86(1.42-5.78)$ & $0.08^{*}(0.01-2.06)$ \\
Nandrolone & $1.61(0.58-4.46)$ & $0.06^{*}(0.02-0.13)$ \\
Nandrolone/stress & $1.99(0.82-4.85)$ & $0.02^{*}(0.01-0.06)$ \\
\hline
\end{tabular}

Data are reported as median, with the $95 \%$ confidence interval in parentheses, for 7-10 animals/group. Acute stress = immobilization for $2 \mathrm{~h}$; physical training $=60$-min swimming session 5 days per week for 8 weeks, with a $5 \%$ body weight load attached to the chest; nandrolone treatment $=$ Deca Durabolin ${ }^{\circledR}, 5 \mathrm{mg} / \mathrm{kg}$ body weight twice per week for 8 weeks, im. ${ }^{*} \mathrm{P}<0.05$ relative to aorta with endothelium (ANOVA and Tukey test). 
training protocol employed here did not change the blood pressure of trained rats in a significant manner compared to the sedentary group. However, a significant increase in systolic blood pressure was observed in both sedentary and trained rats treated with nandrolone, confirming literature findings $(31,32)$.

In the present study, physical exercise also produced an adaptive vascular response characterized by aortic hyporeactivity to noradrenaline, which is dependent on the integrity of endothelial cells. This view is supported by the observation that removal of the endothelium abolished the decreased response of the aorta to noradrenaline that had been induced by the training protocol. A similar hyperactivity of endothelial cells was previously reported in conditions that, like physical exercise $(33,34)$, involve prolonged activation of adrenoceptors such as stress, barodenervation, and pheochromocytoma $(15,19,35)$. In fact, the acute exposure to stress reduced the aortic reactivity to noradrenaline of sedentary rats that was abolished by endothelium removal. These findings support published reports showing a decreased reactivity to vasopressor agents dependent on the integrity of endothelial cells under stress conditions, and confirm earlier findings from our laboratory $(15,19,36)$. Although stress and physical exercise alone induced aortic hyporeactivity to noradrenaline, the association of the two conditions did not result in a synergistic effect.

The literature has shown up-regulation in the expression of endothelial nitric oxide synthase (NOS) mRNA in the thoracic aortas of rats submitted to 4 to 10 weeks of training (37). These results are consistent with other studies that have reported elevated NOS mRNA levels in aortas of exercise-trained dogs, and in coronary resistance vessels of exercise-trained pigs $(38,39)$. The expression of inducible NOS and endothelial NOS mRNA was increased in endothelial cells by chronic treadmill training, whereas chronic exercise blunted phenylephrine-induced vascular responses, probably by increasing nitric oxide release via inducible NOS in the rat thoracic aorta (40). In this context, the training protocol used here may also cause a greater release of nitric oxide, which might reduce or antagonize the vasoconstrictor effect of noradrenaline. This could partially explain the hyporeactivity to noradrenaline observed in the thoracic aorta isolated from trained rats compared to the sedentary group. Similarly to exercise, previous data from our laboratory have shown that hyperactivity of the endothelial nitric oxide pathway is responsible for the

\section{References}

1. Wolfe LA, Cunningham DA. Effects of chronic exercise on cardiac output and its determinants. Can J Physiol Pharmacol 1982; 60: 1089-1097.

2. De Moraes R, Gioseffi G, Nobrega AC, Tibirica E. Effects of exercise training on the vascular reactivity of the whole vascular adaptive response to acute stress $(15,16,19)$. However, the mechanisms involved in the vascular adaptive responses to physical training and stress have not been completely clarified.

With regard to AAS, treatment with nandrolone did not change the aortic reactivity to noradrenaline of sedentary rats. Nevertheless, this treatment prevented the vascular adaptive response induced by physical exercise. In contrast, nandrolone treatment did not change the stress-induced vascular adaptive response in either sedentary or trained rats. In other words, the vascular adaptive response to exercise, but not to stress, was shown to be vulnerable to the deleterious effects of this anabolic steroid. These data suggest different mechanisms for the increased endothelial modulation of vascular responses in physical training and stress. Considering that, in addition to nitric oxide, a major endothelium-relaxing factor, endothelial cells may also produce vasorelaxing factors such as prostacyclin and hyperpolarizing factor, one could hypothesize that the vascular adaptive responses to stress and physical exercise involve distinct vasorelaxing factors. However, we cannot exclude the possibility that the vascular adaptive responses to stress and physical exercise involve the same vasorelaxing factor, probably the nitric oxide that would be produced by an alternative pathway not sensitive to nandrolone in a stress condition.

The present study provides evidence thatAAS-nandrolone prevents the development of vascular adaptations promoted by exercise training without affecting the development of vascular adaptations promoted by stress. If increasing endothelial function is considered to be a beneficial adaptation to both physical exercise and stress, it is concluded that nandrolone administration worsens rat endothelial function during exercise training. In contrast, nandrolone does not represent a risk factor for the vascular adaptive response to stress. The understanding that some adverse conditions in association may represent additional risk factors for a biological system, while others do not, allows us to evaluate which factors in combination would represent the greatest risk for the biological systems and as a consequence could help medical advices to patients.

\section{Acknowledgments}

$$
\text { Research supported by FAPESP (\#06/57200-8). }
$$

kidney circulation in rabbits. J Appl Physiol 2004; 97: 683688.

3. Lenasi $H$, Strucl M. Effect of regular physical training on cutaneous microvascular reactivity. Med Sci Sports Exerc 2004; 36: 606-612. 
4. Schrage WG, Dietz NM, Joyner MJ. Effects of combined inhibition of ATP-sensitive potassium channels, nitric oxide, and prostaglandins on hyperemia during moderate exercise. J Appl Physiol 2006; 100: 1506-1512.

5. Brum PC, Da Silva GJ, Moreira ED, Ida F, Negrao CE, Krieger EM. Exercise training increases baroreceptor gain sensitivity in normal and hypertensive rats. Hypertension 2000; 36: 1018-1022.

6. Collier SR, Kanaley JA, Carhart R Jr, Frechette V, Tobin $\mathrm{MM}$, Hall AK, et al. Effect of 4 weeks of aerobic or resistance exercise training on arterial stiffness, blood flow and blood pressure in pre- and stage-1 hypertensives. J Hum Hypertens 2008; 22: 678-686.

7. Fineschi V, Baroldi G, Monciotti F, Paglicci RL, Turillazzi E. Anabolic steroid abuse and cardiac sudden death: a pathologic study. Arch Pathol Lab Med 2001; 125: 253-255.

8. du Toit EF, Rossouw E, van Rooyen J, Lochner A. Proposed mechanisms for the anabolic steroid-induced increase in myocardial susceptibility to ischaemia/reperfusion injury. Cardiovasc J S Afr 2005; 16: 21-28.

9. Ferrer M, Encabo A, Marin J, Balfagon G. Treatment with the anabolic steroid, nandrolone, reduces vasoconstrictor responses in rabbit arteries. Eur J Pharmacol 1994; 258: 103-110.

10. Ebenbichler CF, Sturm W, Ganzer H, Bodner J, Mangweth B, Ritsch A, et al. Flow-mediated, endothelium-dependent vasodilatation is impaired in male body builders taking anabolic-androgenic steroids. Atherosclerosis 2001; 158: 483-490.

11. Sader MA, Griffiths KA, McCredie RJ, Handelsman DJ, Celermajer DS. Androgenic anabolic steroids and arterial structure and function in male bodybuilders. J Am Coll Cardiol 2001; 37: 224-230.

12. Cunha ST, Moura SCJM, Bernardes FC, Tanno PA, Marcondes KF. Vascular sensitivity to phenilephrine in rats submitted to anaerobic training and nandrolone treatment. Hypertension 2005; 46: 1010-1015

13. Lane HA, Grace F, Smith JC, Morris K, Cockcroft J, ScanIon MF, et al. Impaired vasoreactivity in bodybuilders using androgenic anabolic steroids. Eur J Clin Invest 2006; 36: 483-488.

14. D'Ascenzo S, Millimaggi D, Di Massimo C, Saccani-Jotti G, Botre F, Carta G, et al. Detrimental effects of anabolic steroids on human endothelial cells. Toxicol Lett 2007; 169: 129-136.

15. Cordellini S, Vassilieff VS. Decreased endothelium-dependent vasoconstriction to noradrenaline in acute-stressed rats is potentiated by previous chronic stress: nitric oxide involvement. Gen Pharmacol 1998; 30: 79-83.

16. Cordellini S. Endothelial dysfunction in DOCA-salt hypertension: possible involvement of prostaglandin endoperoxides. Gen Pharmacol 1999; 32: 315-320.

17. Cordellini S, Novo R, Lanza JU. Exposure to stress differential vascular adaptive response in spontaneously hypertensive and Wistar rats: Role of nitric oxide, and prehypertensive and hypertensive states. Life Sci 2006; 79: 646-653.

18. Carrasco GA, Van de Kar LD. Neuroendocrine pharmacology of stress. Eur J Pharmacol 2003; 463: 235-272.

19. Navarro-Oliveira CM, Vassilieff VS, Cordellini S. The sympathetic adrenomedullary system, but not the hypothalamic-pituitary-adrenal axis, participates in aorta adaptive response to stress: nitric oxide involvement. J Auton Neurosci 2000;
83: $140-147$.

20. Medeiros A, Oliveira EM, Gianolla R, Casarini DE, Negrao CE, Brum PC. Swimming training increases cardiac vagal activity and induces cardiac hypertrophy in rats. Braz J Med Biol Res 2004; 37: 1909-1917.

21. Pope HG Jr, Katz DL. Affective and psychotic symptoms associated with anabolic steroid use. Am J Psychiatry 1988; 145: 487-490.

22. Ebal E, Cavalie H, Michaux O, Lac G. Effect of a moderate exercise on the regulatory hormones of food intake in rats. Appetite 2007; 49: 521-524.

23. Noorafshan A, Karbalay-Doust S, Ardekani FM. High doses of nandrolone decanoate reduce volume of testis and length of seminiferous tubules in rats. APMIS 2005; 113: 122125.

24. Tseng YT, Rockhold RW, Hoskins B, Ho IK. Cardiovascular toxicities of nandrolone and cocaine in spontaneously hypertensive rats. Fundam Appl Toxicol 1994; 22: 113-121.

25. Qi Z, Singh J, Handelsman DJ. [Effects of 19-nortestosterone on sex accessory gland growth in hypogonadal mice]. Zhonghua Nan Ke Xue 2002; 8: 241-243.

26. van Dijken HH, de Goeij DC, Sutanto W, Mos J, de Kloet ER, Tilders FJ. Short inescapable stress produces long-lasting changes in the brain-pituitary-adrenal axis of adult male rats. Neuroendocrinology 1993; 58: 57-64.

27. Pertsova SS, Koplik EV, Krause W, Michael N, Oehme P, Sudakov KV. Catecholamines in the adrenals of August and Wistar rats with acute emotional stress. Bull Exp Biol Med 1997; 123: 562-564.

28. Ricart-Jane D, Rodriguez-Sureda V, Benavides A, PeinadoOnsurbe J, Lopez-Tejero MD, Llobera M. Immobilization stress alters intermediate metabolism and circulating lipoproteins in the rat. Metabolism 2002; 51: 925-931.

29. Ghorayebe N, Batloni M, Pinto IMF, Dioguardi G. Left ventricular hypertrophy of athletes. Adaptive physiologic response of the heart. Arq Bras Cardiol 2005; 85: 191-197.

30. Krieger EM, Brum PC, Negrao CE. Role of arterial baroreceptor function on cardiovascular adjustments to acute and chronic dynamic exercise. Biol Res 1998; 31: 273-279.

31. Grace F, Sculthorpe N, Baker J, Davies B. Blood pressure and rate pressure product response in males using highdose anabolic androgenic steroids (AAS). J Sci Med Sport 2003; 6: 307-312.

32. Beutel A, Bergamaschi CT, Campos RR. Effects of chronic anabolic steroid treatment on tonic and reflex cardiovascular control in male rats. J Steroid Biochem Mol Biol 2005; 93: 43-48.

33. Scheurink AJ, Steffens $A B$, Bouritius $H$, Dreteler $G H$, Bruntink R, Remie R, et al. Adrenal and sympathetic catecholamines in exercising rats. Am J Physiol 1989; 256: R155-R160.

34. Scheurink AJ, Steffens AB, Roossien B, Balkan B. Sympathoadrenal function in genetically obese Zucker rats. Physiol Behav 1992; 52: 679-685.

35. Hiremath AN, Hu ZW, Hoffman BB. Desensitization of alphaadrenergic receptor-mediated smooth muscle contraction: role of the endothelium. J Cardiovasc Pharmacol 1991; 18 : 151-157.

36. Jansakul C. Effect of swimming on vascular reactivity to phenylephrine and $\mathrm{KCl}$ in male rats. $\mathrm{Br} \mathrm{J}$ Pharmacol 1995; 115: 587-594.

37. Delp MD, Laughlin MH. Time course of enhanced endotheli- 
um-mediated dilation in aorta of trained rats. Med Sci Sports Exerc 1997; 29: 1454-1461.

38. Sessa WC, Pritchard K, Seyedi N, Wang J, Hintze TH. Chronic exercise in dogs increases coronary vascular nitric oxide production and endothelial cell nitric oxide synthase gene expression. Circ Res 1994; 74: 349-353.

39. Woodman CR, Muller JM, Laughlin MH, Price EM. Induction of nitric oxide synthase mRNA in coronary resistance arteries isolated from exercise-trained pigs. Am J Physiol 1997; 273: $\mathrm{H} 2575-\mathrm{H} 2579$.

40. Yang AL, Tsai SJ, Jiang MJ, Jen CJ, Chen HI. Chronic exercise increases both inducible and endothelial nitric oxide synthase gene expression in endothelial cells of rat aorta. $J$ Biomed Sci 2002; 9: 149-155. 